\title{
Short communication Surrogates are just surrogates, but helpful just the same
} Carol Fabian

The University of Kansas Medical Center, Breast Cancer Prevention Center, 3901 Rainbow Boulevard, Mailstop 5015, Kansas City, Kansas 66160, USA

Corresponding author: Carol Fabian, cfabian@kumc.edu

Published: 20 December 2007

This article is online at http://breast-cancer-research.com/content/9/S2/S18 (c) 2007 BioMed Central Ltd

\section{What is a surrogate end-point biomarker?}

A surrogate end-point biomarker (SEB) may broadly be defined as a predictive measure of a future outcome. For individuals without evidence of cancer, a risk biomarker predicts clinical disease onset. In the case of established cancer, a risk biomarker predicts recurrence or progression. A response biomarker is usually a reversible risk biomarker that predicts disease prevention or, in the case of established cancer, eradication or temporary control.

\section{Properties of surrogate end-point biomarkers}

To be credible, an SEB must have biological plausibility and a strong association with ultimate outcome. To be used for prevention, an SEB should be identified as being causally related to the development of precancer and cancer. Modulation of the SEB through an intervention should predict outcome. The SEB should be reproducible and reliable. Reproducibility is generally maximized with a quantitative biomarker. Optimally, both risk and response SEBs should be prospectively validated in a clinical trial in which the nonsurrogate outcome is also being evaluated [1,2].

\section{Uses of surrogate markers in cancer treatment}

SEBs are used in clinical trials to identify effective new strategies faster and more economically with fewer patients. They may also offer insight into why or why not a particular therapy does not work. In the patient care setting, SEBs are used to determine whether and when to change the therapeutic plan.

In the metastatic setting, typically the same surrogate markers are measured repeatedly to assess response or progression often by imaging and/or physical examination. Two surrogate markers can independently predict the same outcome, but results at any single point in time may be discordant. Consequently, it is important to understand the biology that underlies the surrogate in order to avoid making inappropriate clinical decisions.

In the neoadjuvant setting, a low Ki-67 a few weeks after initiation of treatment and pathological response after several
Breast Cancer Research 2007, 9(Suppl 2):S18 (doi:10.1186/bcr1816)

months of treatment both predict long-term disease-free survival [3-5]. Both biomarkers are currently used in the research setting, and pathological stage after neoadjuvant treatment is used clinically to estimate distant disease-free survival. It is probable that, in the near future, early reduction in breast proliferation will be used along with clinical indices to determine whether to switch antihormonal or chemotherapeutic treatment during the neoadjuvant period. Pathological response after neoadjuvant chemotherapy will also probably be used to determine whether to administer additional chemotherapy adjuvantly to women with hormone receptor negative tumours (Figure 1).

\section{Use of surrogate markers in cancer prevention}

Perhaps the greatest need for surrogate biomarkers is in the prevention setting, where the traditionally measured outcome of cancer occurs infrequently and only after a long latent period. Biomarkers that accurately predict short-term risk are needed in order to avoid treating healthy women with drugs tthat most do not need in order to benefit a few. Reversible risk biomarkers could be used to monitor response for those individuals undergoing the intervention.

\section{Prevention risk biomarkers}

Serum levels of insulin-like growth factor (IGF)-1, the ratio of IGF-1 to its binding protein IGFBP-3, serum luteal phase progesterone and free testosterone in premenopausal women, and prolactin and bioavailable oestradiol and testosterone in postmenopausal women are examples of risk biomarkers that can be measured with a simple blood test [6]. However, the two biomarkers associated with the greatest relative risk for invasive cancer and likely to be most reflective of events at the level of the breast are mammographic density and intraepithelial neoplasia.

Mammographic density is reflective of the amount of stroma, epithelium and fluid in the breast relative to fat. There are both qualitative and quantitative means of measuring mammographic density $[7,8]$. Using the computer-assisted method of 
Figure 1

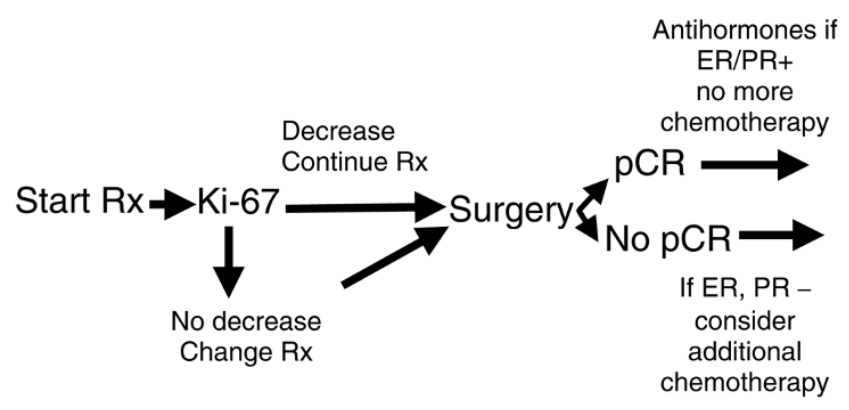

Surrogate response biomarkers will guide neoadjuvant treatment. ER, oestrogen receptor; $\mathrm{pCR}$, pathological complete response; PR, progesterone receptor; Rx, treatment.

Boyd and Yaffee, women with more than 75\% area of increased density have an approximate fivefold increase in risk relative to those with no increased density (that is, a completely fatty breast). Mammographic density has been shown to increase modestly the concordance statistic associated with Gail model predicted probability, and thus it should improve the accuracy of individual risk estimates $[9,10]$. The advantages of mammographic density as an SEB is that it is quantitative, positively associated with some risk factors (including benign breast disease, and oestrogen and progestin combined hormone replacement therapy $[11,12]$ ) and can be obtained at minimal extra cost and with no extra procedure in screened women.

The disadvantages are that it is negatively correlated with some risk factors, including age and obesity, and may be negatively correlated with free oestradiol. There is substantial technical and interpretive variance, and it is unclear whether effective agents such as tamoxifen and raloxifene reduce density in postmenopausal women over 55 years old [13-16]. Cuzick and coworkers [15] suggested that reduction in density is associated with only one-third of the risk reduction resulting from tamoxifen administration.

It is quite possible that density results from the interplay of stromal and epithelial mitogens such as IGF-1, oestrogen and progestin, such that if one or more of the factors is low at baseline and/or is unaffected by the prevention intervention, then no change may occur in density, although risk may be diminished.

\section{Intraepithelial neoplasia obtained by nonlesion directed sampling}

The findings of hyperplasia and atypical hyperplasia in a diagnostic biopsy are associated with an approximate twofold and fivefold subsequent increase in risk for breast cancer, respectively [6]. Because most women have not had a diagnostic biopsy, another method is required to obtain tissue for risk stratification and for monitoring a prevention intervention.

Both nipple aspirate fluid (NAF) and random periareolar fine needle aspiration (RPFNA) evidence of atypia have been shown to increase the concordance statistic based on the Gail model [17-19]. NAF harvest is noninvasive and inexpensive, but the majority of NAF samples have no or few cells whereas more than $90 \%$ of RPFNA samples are cellular [17]. The advantages of breast tissue sampling by RPFNA for risk and response biomarkers is that it provides a direct assessment of precancerous change as well as tissue for other response and predictive markers such as Ki-67 and oestrogen receptor (ER), and there is minimal discomfort. Disadvantages are that it does involve a procedure that requires training, and there is both intra- and inter-observer interpretive variance.

\section{Use of breast density and breast tissue biomarkers in phase II prevention trials}

Arzoxifene is a third-generation selective oestrogen receptor modulator (SERM) similar to raloxifene but with greater potency, primarily because of greater bioavailability. We assessed the effect of 6 months of arzoxifene compared with placebo on several risk biomarkers as part of a multiinstitutional National Cancer Institute sponsored phase II prevention trial [20]. Compared with placebo, there was no change in cytomorphology index score, but there was a significant favorable modulation of mammographic breast density, breast tissue ER expression and serum IGF-1/ IGFBP-3 ratio. These changes were more marked in premenopausal than in postmenopausal women. Arzoxifene is being further assessed in a phase III prevention trial with incidence of bone fracture and breast cancer as two coprimary end-points.

From the arzoxifene phase II trial we learned that change in biomarker expression may vary with menopause status and that cytomorphology change is not a sensitive indicator of SERM bioactivity after short-term administration. Expression of Ki-67 and ER increase with morphological abnormality in benign breast tissue whether sampled by diagnostic biopsy or RPFNA [21-23]. Consequently, changes in Ki-67 and ER expression were explored as end-points for phase II trials with antihormonal agents in our trial of letrozole in high-risk women on HRT. Ki-67 is also higher in premenopausal than in postmenopausal women [22]. The concept of using letrozole in high-risk women taking hormone replacement therapy (HRT) has been shown to be valid in hormonally intact aromatase over-expressing mice [24]. Postmenopausal women produce the majority of breast oestrogen locally via aromatase and sulfatase [25] and aromatase activity is increased in precancerous breast tissue [26].

We found a significant decrease in benign breast tissue Ki67 (mean 5.1\% at baseline and 1.5\% after 6 months of 
Table 1

\begin{tabular}{lcc}
\multicolumn{3}{l}{ Biomarker change by antihormone type and menopause } \\
\hline Biomarker and menopause status & Tamoxifen & $\begin{array}{c}\text { Aromatase } \\
\text { inhibitor }\end{array}$ \\
\hline Breast density premenopause & Marked & NA \\
Breast density postmenopause & Minimal & $?$ \\
Serum IGF-1/IGFBP3 ratio & Decrease & No change \\
Serum $E_{2}$ premenopause & Large increase & NA \\
Serum $E_{2}$ postmenopause (no HRT) & Slight increase & Decrease \\
Reverse atypia in 6 to 12 months & Doubtful & Doubtful \\
\hline
\end{tabular}

$E_{2}$, oestradiol; IGF, insulin-like growth factor; HRT, hormonre replacement therapy; IGFBP, IGF-1 binding protein; NA, not applicable.

letrozole) in 42 high-risk women on a stable dose of hormone replacement. There was no significant accompanying change in serum oestradiol, IGF-1, the IGF-1/IGFBP-3 ratio, or mammographic breast density [27]. Cytomorphology designation was likewise unchanged after 6 months of letrozole, although the proportion of abnormal cells in the specimens by karyometry was reduced from baseline [28]. Given our pilot study results, the concept of utilizing letrozole to reduce breast cancer risk in women on HRT is being tested further in a multi-institutional placebo controlled trial sponsored by the US National Cancer Institute.

\section{Conclusion}

Modulation of an individual surrogate response biomarker is likely to be dramatically influenced by agent, menopause status and baseline characteristics of the cohort (Table 1). Biomarkers are extremely valuable in initial testing of new strategies, particularly in prevention. However, it is important to understand how the agents may differentially modulate risk biomarkers, so that an effective agent is not discarded because it does not favourably modulate all risk biomarkers. Currently, response biomarkers for prevention are utilized only within the context of phase I and II trials. Surrogate markers in metastatic disease and in the neoadjuvant arena are helpful both for research and in clinical decision making.

\section{Acknowledgement}

This article has been published as part of Breast Cancer Research Volume 9 Supplement 2, 2007: Controversies in Breast Cancer. The full contents of the supplement are available online at http://breastcancer-research.com/supplements/9/S2.

\section{References}

1. Kelloff GJ, Sigman CC, Johnson KM, Boone CW, Greenwald P, Crowell JA, Hawk ET, Doody LA: Perspectives on surrogate end points in the development of drugs that reduce the risk of cancer. Cancer Epidemiol Biomarkers Prev 2000, 9:127-137.

2. Fabian CJ, Kimler BF: Selective estrogen receptor modulators for primary prevention of breast cancer. J Clin Oncol 2005, 23: 1644-1655.

3. Dowsett M, Smith IE, Ebbs SR, Dixon JM, Skene A, Griffith C,
Boeddinghaus I, Salter J, Detre S, Hills M, et al.: Proliferation and apoptosis as markers of benefit in neoadjuvant endocrine therapy of breast cancer. Clin Cancer Res 2006, 12:1024s1030s.

4. Chang J, Ormerod M, Powles TJ, Allred DC, Ashley SE, Dowsett $\mathrm{M}$ : Apoptosis and proliferation as predictors of chemotherapy response in patients with breast carcinoma. Cancer 2000, 89: 2145-2152.

5. Carey LA, Metzger R, Dees EC, Collichio F, Sartor Cl, Ollila DW, Klauber-DeMore N, Halle J, Sawyer L, Moore DT, et al.: American Joint Committee on Cancer tumor-node-metastasis stage after neoadjuvant chemotherapy and breast cancer outcome. J Natl Cancer Inst 2005, 97:1137-1142.

6. Fabian CJ, Kimler BF, Mayo MS, Khan SA: Breast-tissue sampling for risk assessment and prevention. Endocr Relat Cancer 2005, 12:185-213.

7. McCormack VA, dos Santos Silva I: Breast density and parenchymal patterns as markers of breast cancer risk: a meta-analysis. Cancer Epidemiol Biomarkers Prev 2006, 15: 1159-1169.

8. Boyd NF, Byng JW, Jong RA, Fishell EK, Little LE, Miller AB, Lockwood GA, Tritchler DL, Yaffe MJ: Quantitative classification of mammographic densities and breast cancer risk: results from the Canadian National Breast Screening Study. J Natl Cancer Inst 1995, 87:670-675.

9. Tice JA, Cummings SR, Ziv E, Kerlikowske K: Mammographic breast density and the gail model for breast cancer risk prediction in a screening population. Breast Cancer Res Treat 2005, 94:115-122.

10. Chen J, Pee D, Ayyagari R, Graubard B, Schairer C, Byrne C, Benichou J, Gail MH: Projecting absolute invasive breast cancer risk in white women with a model that includes mammographic density. J Natl Cancer Inst 2006, 98:1215-1226.

11. Byrne C, Schairer C, Brinton LA, Wolfe J, Parekh N, Salane M, Carter C, Hoover R: Effects of mammographic density and benign breast disease on breast cancer risk (United States). Cancer Causes Control 2001, 12:103-110.

12. Chlebowski RT, Hendrix SL, Langer RD, Stefanick ML, Gass M, Lane D, Rodabough RJ, Gilligan MA, Cyr MG, Thomson CA, et al.; WHI Investigators: Influence of estrogen plus progestin on breast cancer and mammography in healthy postmenopausal women: the Women's Health Initiative Randomized Trial. JAMA 2003, 289:3243-3253.

13. Ciatto S, Houssami N, Apruzzese A, Bassetti E, Brancato B, Carozzi F, Catarzi S, Lamberini MP, Marcelli G, Pellizzoni R, et al: Categorizing breast mammographic density: intra- and interobserver reproducibility of BI-RADS density categories. Breast 2005, 14:269-275.

14. Berg WA, Campassi C, Langenberg P, Sexton MJ: Breast imaging reporting and data system: inter- and intraobserver variability in feature analysis and final assessment. $A J R A m J$ Roentgenol 2000, 174:1769-1777.

15. Cuzick J, Warwick J, Pinney E, Warren RM, Duffy SW: Tamoxifen and breast density in women at increased risk of breast cancer. J Natl Cancer Inst 2004, 96:621-628.

16. Freedman M, San Martin J, O'Gorman J, Eckert S, Lippman ME, Lo SC, Walls EL, Zeng J: Digitized mammography: a clinical trial of postmenopausal women randomly assigned to receive raloxifene, estrogen, or placebo. J Natl Cancer Inst 2001, 93: 51-56.

17. Tice JA, Miike R, Adduci K, Petrakis NL, King E, Wrensch MR: Nipple aspirate fluid cytology and the Gail model for breast cancer risk assessment in a screening population. Cancer Epidemiol Biomarkers Prev 2005, 14:324-328.

18. Fabian CJ, Kimler BF, Zalles CM, Klemp JR, Kamel S, Zeiger S, Mayo MS: Short-term breast cancer prediction by random periareolar fine-needle aspiration cytology and the Gail risk model. J Natl Cancer Inst 2000, 92:1217-1227.

19. Mayo MS, Kimler BF, Fabian CJ: Evaluation of models for the prediction of breast cancer development in women at high risk of breast cancer. J Applied Res 2001, 1:37-44.

20. Fabian CJ, Kimler BF, Anderson JR, Chamberlain C, Mayo MS, Zalles CM, O'Shaughnessy JA, Lynch HT, Johnson KA, Browne D: Phase II breast cancer chemoprevention trial of the third generation selective estrogen receptor modulator arzoxifene [abstract 1001]. J Clin Onco/ 2006, 24(suppl 18S):49s.

21. Allred DC, Mohsin SK, Fuqua SA: Histological and biological 
evolution of human premalignant breast disease. Endocr Relat Cancer 2001, 8:47-61.

22. Khan OJ, Kimler BF, Clark J, Metheny T, Zalles CM, Fabian CJ: Ki67 Expression in benign breast ductal cells obtained by random periareolar fine needle aspiration. Cancer Epidemiol Biomarkers Prev 2005, 14:786-789.

23. Sharma P, Kimler BF, Warner C, Metheny T, Xue Q, Zalles CM, Fabian CJ: Estrogen receptor expression in benign breast ductal cells obtained from random periareolar fine needle aspiration correlates with menopausal status and cytomorphology index score. Breast Cancer Res Treat 2006, 100:7176.

24. Tekmal RR, Kirma N, Gill K, Fowler K: Aromatase overexpression and breast hyperplasia, an in vivo model: continued overexpression of aromatase is sufficient to maintain hyperplasia without circulating estrogens, and aromatase inhibitors abrogate these preneoplastic changes in mammary glands. Endocr Relat Cancer 1999, 6:307-314.
25. Ernster VL, Wrensch MR, Petrakis NL, King EB, Miike R, Murai J, Goodson WH 3rd, Siiteri PK: Benign and malignant breast disease: initial study results of serum and breast fluid analyses of endogenous estrogens. J Natl Cancer Inst 1987, 79: 949-960.

26. Santen RJ, Martel J, Hoagland M, Naftolin F, Roa L, Harada N Hafer L, Zaino R, Pauley R, Santner S: Demonstration of aromatase activity and its regulation in breast tumor and benign breast fibroblasts. Breast Cancer Res Treat 1998, 49:S93-S99.

27. Fabian CJ, Kimler BF, Zalles CM, Khan QJ, Mayo MS, Phillips TA, Simonsen M, Metheny T, Petroff BK: Reduction in proliferation with six months of letrozole in women on hormone replacement therapy. Breast Cancer Res Treat 2007, 106:75-84.

28. Bartels PH, Fabian CJ, Kimler BF, Ranger-Moore JR, Frank DH Yozwiak ML, Alberts DS: Karyometry of breast epithelial cells acquired by random periareolar fine needle aspiration in women at high risk for breast cancer. Anal Quant Cytol Histol 2007, 29:63-70. 